\title{
Soft start-up strategy of pulse-density-modulated series- resonant converter for induction heating application
}

\author{
Pavlo Herasymenko, Volodymyr Pavlovskyi
}

Department of Transistor Converters, Institute of Electrodynamics, Kyiv, Ukraine

\begin{tabular}{l}
\hline \hline Article Info \\
\hline Article history: \\
Received Jun 16, 2020 \\
Revised Jan 21, 2021 \\
Accepted Feb 2, 2021 \\
\hline
\end{tabular}

\section{Keywords:}

Phase-locked loops Pulse-density modulation Pulse-density-modulated converter

Series-resonant inverter Start-up strategy

\begin{abstract}
This paper presents a soft start-up strategy of pulse-density-modulated seriesresonant converter for induction heating application. The pulse-density modulation (PDM) technique is widely used in converters based on voltagesource series-resonant inverters (SRIs) to control the output current or power. However, during a start-up process, PDM has some disadvantages both in inrush current limiting and providing a zero-voltage switching operation of SRI transistors. In the paper, different PDM techniques are considered and basic moments of PDM using within the start-up process are analyzed. A new soft start-up strategy of PDM converter for induction heating application is proposed. The main features of the proposed strategy include an interleaved or a stepped PDM control, an initial combination of PDM at the beginning of the start-up process, and an operating algorithm during the start-up process. The proposed strategy was verified by a $2.5 \mathrm{~kW}$ experimental setup of the pulsedensity-modulated interleaved converter with an operating frequency from 50 $\mathrm{kHz}$ up to $100 \mathrm{kHz}$. Experimental results confirm the effectiveness of the proposed start-up strategy and show that the maximum current amplitude within start-up processes exceeds the maximum steady-state current amplitude by no more than $30 \%$.
\end{abstract}

This is an open access article under the CC BY-SA license.

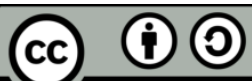

\section{Corresponding Author:}

Pavlo Herasymenko

Department of Transistor Converters

Institute of Electrodynamics

03057, 56 Peremohy avenue, Kyiv, Ukraine

Email: herasymenko@ieee.org

\section{INTRODUCTION}

Modern MOSFETs and IGBTs allow to create powerful high-frequency transistor converters. Such converters are increasingly used in various applications, in particular in induction heating systems. For these systems transistor converters based on the voltage-source or the current-source inverter are widely used. A start-up process is very important for transistor converters, especially to limit their inrush current. Furthermore, hard-switching operation modes of transistors under the start-up process may arise due to features of some control techniques. Therefore, the start-up process can be a difficult problem in power converters. Depending on which control technique is used to regulate the output current of the inverter, it is possible to obtain different switching modes of the inverter transistors both during the start-up process and in the steady-state mode. Many different control techniques have been proposed to regulate the output current or power of these converters, some of which make it possible to provide zero-voltage switching (ZVS) and/or zero-current switching (ZCS) operation modes. ZVS/ZCS makes it possible to substantially reduce power losses in the converters with highfrequency operation modes. The advantage of converters based on the voltage-source series-resonant inverter (SRI) is that they have a simple power circuit configuration and regulation of its output current or power can 
be implemented in many ways: pulse-frequency modulation, pulse-width modulation, phase-shift control, pulse-density modulation (PDM), and combinations of the mentioned above methods or some of their variations [1]-[16].

In recent years, one of the most frequently used techniques for regulating output current in voltagesource SRIs is PDM [14]-[21]. The advantage of the PDM SRI is ZVS and quasi-ZCS [15], [22]. It should be noted that the SRI must operate with a lagging power factor so that the transistor commutation is completed before its current falls to zero [23]. Lossless snubbing circuits are often used to reduce electromagnetic interference in PDM SRIs [16], [22], [24]. The use of these circuits allows to reduce $d v / d t$ and surge voltage across the transistor, as well as commutation losses of the SRI transistors. However, the use of the PDM technique has its disadvantages. The main one is the appearance of an SRI current amplitude fluctuation. This fluctuation affects the maximum voltage applied to the capacitor $C$ of the series-resonant circuit, the switching modes of the SRI transistors, and the power loss in these transistors. Under low quality factor $Q$ of the seriesresonant circuit, it can be a significant problem. The authors of [16]-[18], [20], [25]-[27] deal with ways to reduce the current amplitude fluctuation by improving control methods on the basis of traditional PDM. Another disadvantage of PDM using is that at a frequency much higher than the resonant frequency of the series-resonant circuit it is possible to get NON-ZVS commutation modes, especially during the start-up process. A soft start-up process plays an important role in limiting the maximum value of the output current amplitude of the SRI, especially when the induction heating equipment works on a workpiece-free induction coil. In such a case, the amplitude of the inrush current may reach several times the steady-state current amplitude. The appearance of the excessive inrush current during start-up processes may cause the failure of the SRI transistors and/or overvoltage on the capacitor $C$ before the control system is able to limit the current by one of the commonly used techniques.

An implementation option of the soft start-up process is the gradual voltage increase of the power source [28]. The main disadvantage of this approach is the need to have a regulated power source. Another option is the frequency-decreasing method [15], [29]. In this case, the initial frequency of the converter must be far from the resonant one. However, it is not always possible because the induction heating equipment is to operate over a wide frequency range. It is possible to use phase-shift control to provide soft start-up process, but in this case the initial frequency has also be higher than the resonant frequency to provide ZVS, and the lower the value of $Q$ and higher the value of the inverter output current, the higher the initial frequency must be.

This article builds upon the ideas of our preliminary work presented in [30], that showed the key features of control to limit the inrush current of the PDM converter. This paper extends the analysis of PDM control techniques, in particular, comparing the interleaved PDM control with the stepped one for the modular converter, extends the discussion of the start-up process of the converter with PDM control technique for more in-depth investigation. The main contribution of this paper is a new soft start-up strategy of PDM converter for induction heating application. All steps of the proposed start-up strategy are presented through an algorithm. The main novelties of this strategy are as follows: 1) selecting the suitable PDM control technique and combinations of PDM parameters which provide fewer amplitude fluctuations and the free-wheeling interval duration of the converter output current; 2) using the modular converter based on the series connection of inverters, and using the interleaved or stepped PDM control for this converter; 3) the start-up process begins from the maximum frequency and with the selected initial combination of PDM parameters. Enhanced experimental validations are also provided to verify the performance of the proposed strategy.

\section{SYSTEM DESCRIPTION AND OPERATION PRINCIPLE}

\subsection{System configuration}

A load of induction heating equipment (an induction coil and a workpiece) is usually modelled as a series connection of the equivalent inductor $L$ and equivalent resistor $R$, based on its analogy with respect to a transformer, and it is defined by values of the equivalent inductance $L$ and equivalent resistance $R$ as shown in Figure 1. The resistance $R$ represents the resistance of an inserted workpiece into an induction coil and the resistance of the coil itself. The inductance $L$ represents inductances of the workpiece, coil, and air gap between the workpiece and induction coil. Values of $R$ and $L$ depend on the coil and workpiece geometries and materials, operating frequency of the process and other parameters. In series-resonant circuits, the inductor $L$ and the resistor $R$ are connected in series with the capacitor $C$. Figure 1 shows the basic circuit configuration of the induction heating equipment based on the SRI. The configuration includes a diode bridge rectifier, a DC-filter, a full bridge series-resonant inverter (FB-SRI), a matching transformer, and a control system. The matching transformer is used for galvanic isolation and impedance matching. A blocking capacitor $C_{b}$ is needed to avoid the appearance of the DC component on the primary winding of the matching transformer. 


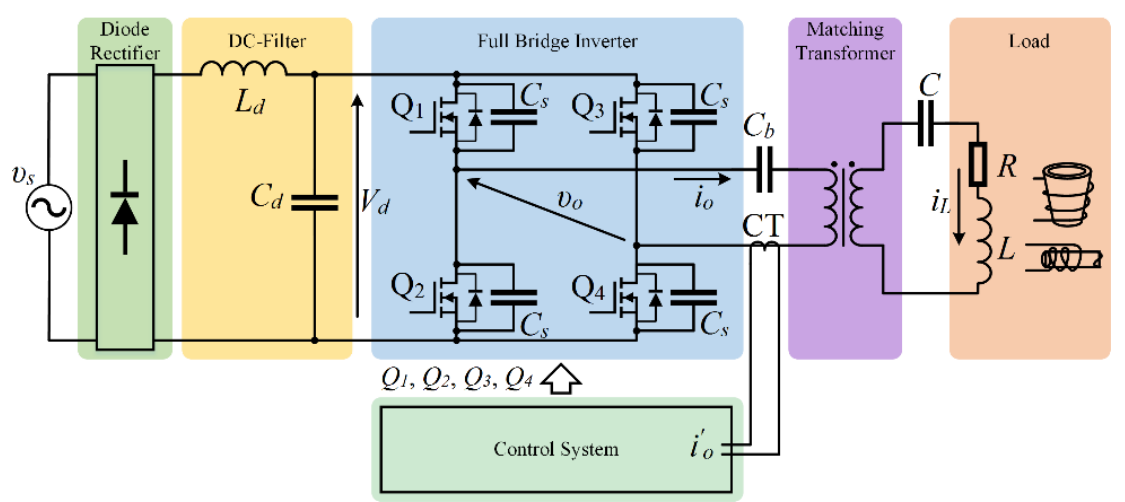

Figure 1. The basic circuit configuration of the induction heating equipment based on the SRI

\subsection{Analysis of PDM techniques}

Figure 2 depicts the PDM signal $v_{P D M}$, the gate control signals $\left(Q_{1}, Q_{2}, Q_{3}, Q_{4}\right)$ of SRI transistors, and the voltage $v_{O}$ and current $i_{O}$ waveforms at the inverter output under PDM in the steady-state mode. The modulation period $T_{M}$ of $v_{O}$ contains two intervals: the ON-state time interval $T_{O N}$ (PDM works by connecting the load to the source during $m$ cycles of the period $T_{S w}$ of $v_{O}$ within $T_{O N}$ ) and the OFF-state interval $T_{O F F}$ (PDM works on the short-circuited load during $n$ cycles of $T_{S w}$ within $\left.T_{O F F}\right) . T_{O N}$ can also be named as an injection interval, because the energy on this interval is transmitted from the source into the series-resonant circuit; $T_{O F F}$ can also be named as a free-wheeling interval, because at this interval the energy being stored in the capacitor $C$ at the end of $T_{O N}$ is dumped into the resistance $R$. The presence of these two intervals causes the amplitude fluctuation of $i_{O}$, and the lower the quality factor $Q$ is, the greater is the fluctuation. The SRI output current or power regulation is carried out by changing the $T_{O N}$ and $T_{O F F}$ durations within $T_{M}$.

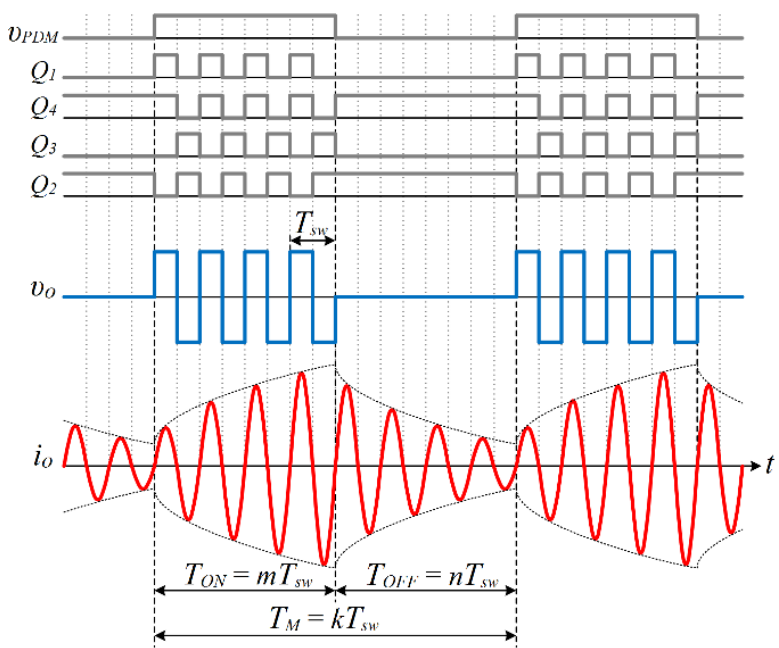

Figure 2. Pattern of drive sequences, voltage $v_{O}$ and current $i_{O}$ waveforms under the PDM operation

It is convenient to evaluate the modulation period $T_{M}$, interval $T_{O N}$, and interval $T_{O F F}$ with the aid of numbers that are corresponded with the quantity of $T_{s w}$ as shown in Figure 2:

$m=T_{O N} / T_{s w}, n=T_{O F F} / T_{s w}, k=T_{M} / T$

Where $k=m+n$ is a number of cycles having the period $T_{s w}$ within $T_{M}$.

There are turn-off losses, no turn-on ones, and no reverse-recovery problem with antiparallel diodes in the case of operating with a lagging power factor [8], [23], [31]. This mode is preferred at high frequencies. 
To make the switching process closer to optimum, it is advisable to change the dead-time $T_{D T}$ between the SRI transistor control signals during the work process [6], [18]. In practice, under the steady-state mode the SRI operating frequency $\omega_{s w}=(2 \pi) / T_{s w}$ is close to the resonance frequency $\omega_{r}=1 / \sqrt{L C}$ of the series-resonant circuit. The case of PDM technique in which $m, n$, and $k$ are only integers, is often named in the literature as a "standard" or "traditional" PDM (Case I in Figure 3) [18], [20], [26]. The pulse density D of PDM can be expressed as (2)

$$
D=T_{O N} / T_{M}=m / k
$$

In [17], the PDM technique (where $n$ are only integers, $m$ and $k$ are multiples of 0.5 ) for decreasing the amplitude fluctuation is analyzed in detail (Case II in Figure 3).

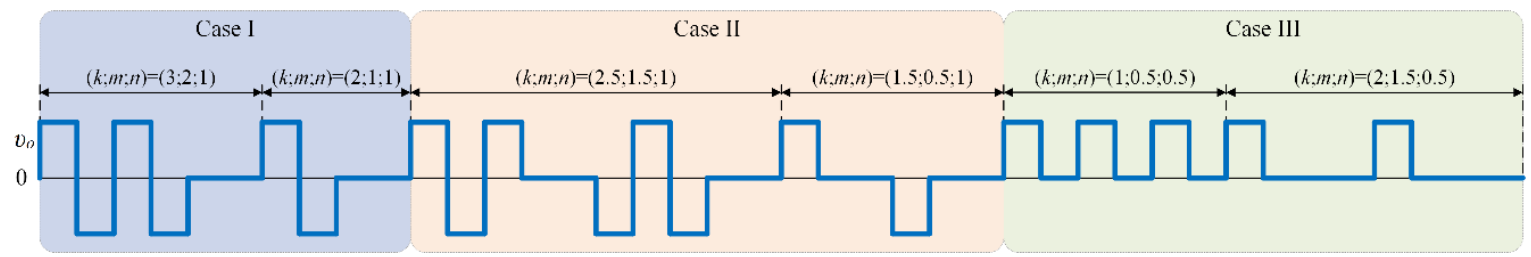

Figure 3. Waveforms of $v_{O}$ in case of different PDM techniques

The lowest amplitude fluctuation of $i_{O}$ can be achieved when $n$ and $m$ are multiples of 0.5 and the value of $k$ can be both an integer and a multiple of 0.5 as shown in Case III in Figure 3 [16], [18], [25]. In this case, most pattern variants of $v_{O}$ can be obtained, since such the case includes all the combinations $(k ; m ; n)$ of the first two cases. Some authors name this PDM technique as "asymmetrical frequency modulation" (which is owing to the obtained pattern of $v_{O}$ ) [16], other authors - as "enhanced pulse density modulation" (because smaller current amplitude fluctuations compared to the traditional PDM can be achieved) [18]. The authors of [20] this PDM case regard as one of three operation modes of their improved PDM and name this mode of operation as "semi mode". However, in this case, the voltage $v_{O}$ may contain a dc component. It should be paid a careful attention for choosing the capacitance of $C_{b}$. On the one hand, the larger value of $C_{b}$ allows to reduce the maximum voltage on the primary winding of the matching transformer. On the other hand, this can lead to core saturation of the matching transformer under the change of $(k ; m ; n)$ during operation and, especially, during the start-up process. This type of PDM is convenient when it is no need to use the matching transformer.

Both Cases II and III are advanced versions of the traditional PDM. The same density $D$ can be achieved under different combinations of $(k ; m ; n)$. Therefore, it is advisable to choose the combination of $(k$; $m ; n)$ providing the fewer free-wheeling interval and amplitude fluctuation of $i_{O}$ [17], [25], [27]. In order to ensure a more uniform control characteristic, it is expedient to combine nearby combinations $(k ; m ; n)$ to obtain additional characteristic points, and some of them can be excluded.

\subsection{Drawback of PDM under Start-up Process}

In order to provide ZVS operating during the start-up process, it is necessary to get a current lagging. For this purpose, it is advisable to set the initial frequency $\omega_{i n i}$ of the SRI to the maximum, which has to be greater than $\omega_{s w}$. Generally, a frequency tracking system for the SRI is based on a phase-locked-loop (PLL) technique that tracks the phase shift between $v_{O}$ and $i_{O}$. As a rule, this tracking system is realized by PLLintegrated circuits, digital controllers or field-programmable gate arrays [19], [32], [33]. It may be too high inrush current depending on: the value of $\omega_{i n i}$ (how close it is to $\omega_{s w}$ ), the quality factor $Q$, and the inertia of the control system for determining the error signal between the measured level of $i_{O}$ and the task signal as shown in Figure 4(a). In this case, it is available to start work with the initial PDM combination to prevent an excessive high inrush current. The use of such a combination of PDM makes it possible to limit inrush current during start-up processes even if $\omega_{\text {ini }}$ is close to $\omega_{s w}$.

However, if the frequency $\omega_{s w}$ during the steady-state mode is much lower than $\omega_{i n i}$, NON-ZVS commutation modes of inverter transistors during the start-up process may occur, in particular, reverserecovery problems with antiparallel diodes as shown in Figure 4(b). This is because free damped current oscillations occur at the $T_{O F F}$, with frequency

$$
\omega_{d}=\omega_{r} \sqrt{1-\xi^{2}}
$$


Where $\xi=\frac{R}{2} \sqrt{\frac{C}{L}}$ is the damping factor.

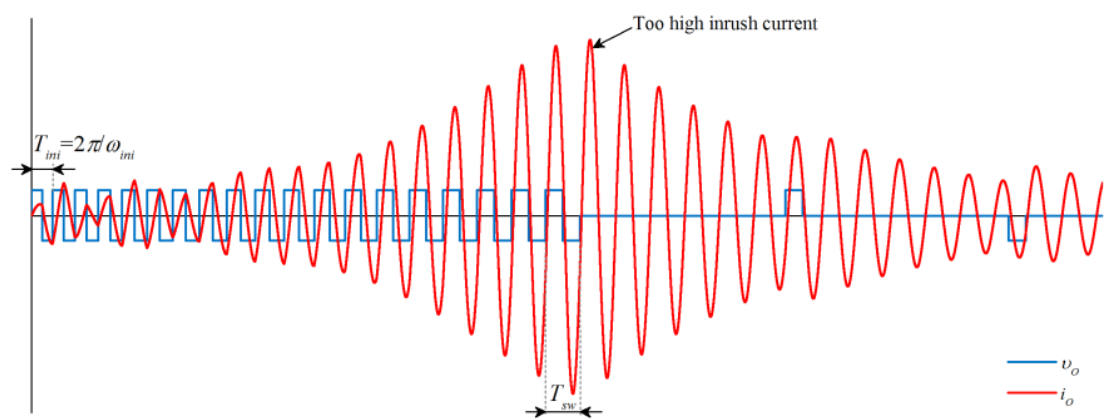

(a)

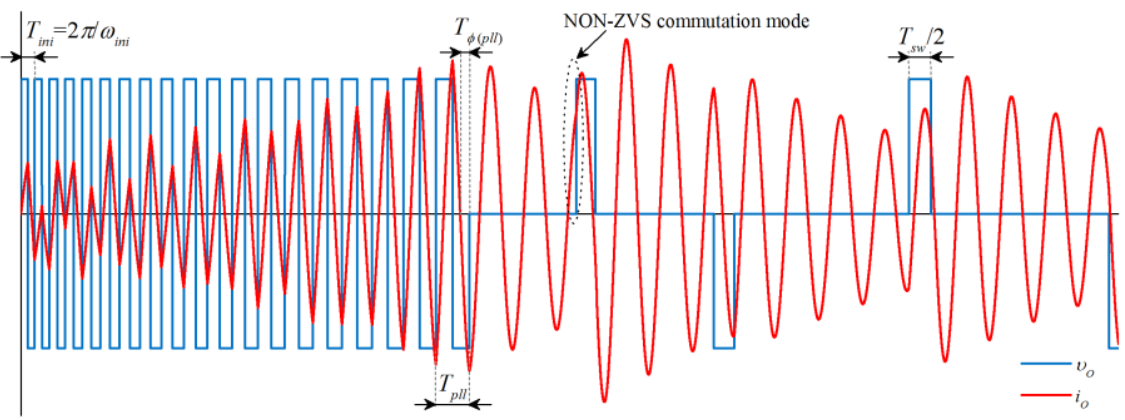

(b)

Figure 4. Waveforms of start-up processes under PDM, (a) $\omega_{\text {ini }}$ is close to $\omega_{s w}$, (b) $\omega_{\text {ini }}$ is much higher than $\omega_{s w}$

Within the start-up process, when the control system would start to use PDM, after $T_{O F F}$ at the beginning of the next $T_{O N}$ a time shift $T_{\varphi}$ between $v_{O}$ and $i_{O}$ will occur. The value of $T_{\varphi}$ can be defined as

$$
T_{\varphi}=2 \pi n\left(\frac{1}{\omega_{d}}-\frac{1}{\omega_{p l l}}\right)+T_{\phi(p l l)}
$$

Where $\omega_{p l l}$ is the fundamental frequency of $v_{O}$ at the beginning of $T_{O F F}, T_{\phi(p l l)}$ is the time shift between the fundamental frequencies of $v_{O}$ and $i_{O}$ at the beginning of $T_{O F F}$. NON-ZCS commutation modes of the transistors will occur provided that

$$
T_{\varphi} \geq \frac{T_{p l l}}{2} \rightarrow n \geq \frac{\frac{T_{p l l}}{2}-T_{\phi(p l l)}}{T_{d}-T_{p l l}}
$$

Where $T_{d}=2 \pi / \omega_{d}$ is the period of damped current oscillation, $T_{p l l}=2 \pi / \omega_{p l l}$ is the period of $v_{O}$ at the beginning of $T_{O F F}$. For providing ZVS operating it is necessary to compensate $T_{\varphi}$, for this the PLL tracking system during $T_{O F F}$ has to make the frequency of its generator close to $\omega_{d}$. In practice, under small values of $n$, this is a difficult task; in addition, the phase shift between $v_{O}$ and $i_{O}$ is usually realized by the PLL system when changing of $\omega_{\text {pll }}$ is being fulfilled with the aid of the proportional-integral (PI) control.

\subsection{Interleaved and stepped PDM controls}

To reduce the current amplitude fluctuation and the duration of the free-wheeling interval, it is advisable to use an interleaved PDM control [20], [34], [35]. This kind of PDM control is suitable for converters 
which are based on series or parallel connection of inverters. The use of interleaving between the PDM control of each channel of a modular converter to reduce the voltage ripple is considered in [20] and to increase the frequency of the converter - in [34]. The basic idea of the interleaved PDM control is that each channel of $N$ inverters has the same pattern of the PDM signals and there is the time shift $S$ between them; besides, the latter is the multiple of $T_{s w}$. Figure 5 shows a modular converter based on the series connection of two SRIs $(N=2)$ and Figure 6 depicts the output voltages of each channel $\left(v_{O 1}, v_{O 2}\right)$, load current $\left(i_{L}\right)$, and total output voltage of the modular converter $v_{\text {total }}$ under interleaved PDM. The pattern of $v_{\text {total }}$ depends on the number $N$ of seriesconnected inverters and the shift $S$ between their PDM signals.

In Figure 6 it is shown the dependence of the $v_{\text {total }}$ pattern on several combinations of $(k ; m ; n)$ and different values of $S$. Providing of $S$ allows to decrease the durations of the free-wheeling interval of $i_{L}$ and output currents of inverters $\left(i_{O 1}, i_{O 2}\right)$, respectively, as well as to decrease their amplitudes fluctuations. Under different values of $S$ and the same combination of $(k ; m ; n)$ the results may be the same or different. It is advisable to choose $S$ in such a way to provide the least free-wheeling interval and amplitude fluctuation.

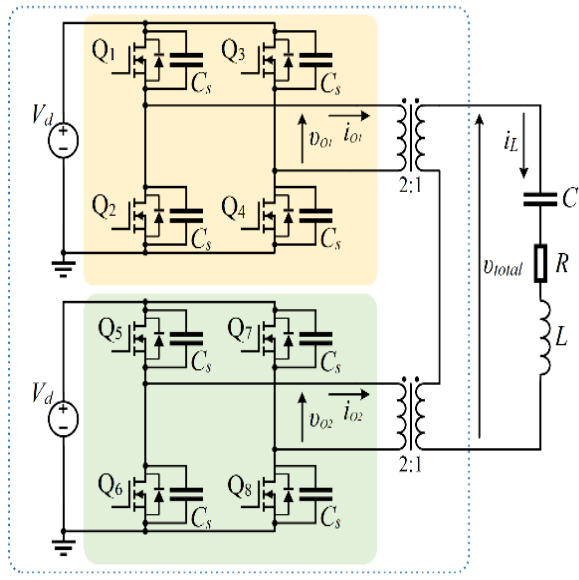

Figure 5. Modular converter based on the series connection of two SRIs

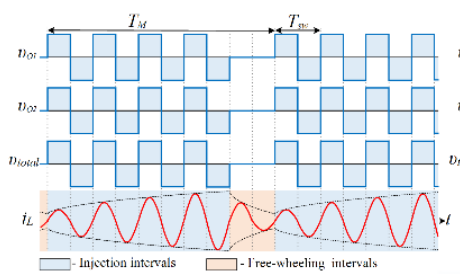

(a)

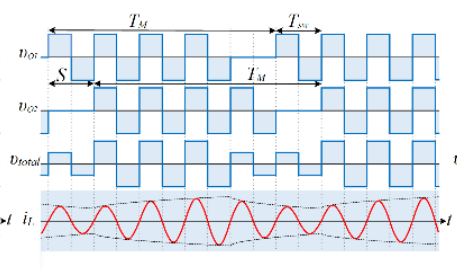

(b)

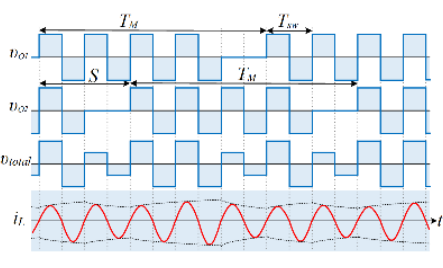

(c)

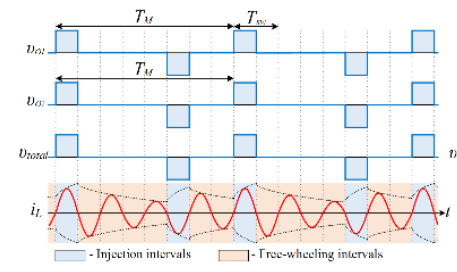

(d)

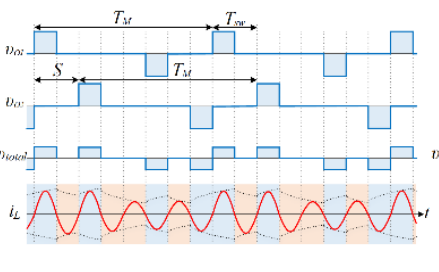

(e)

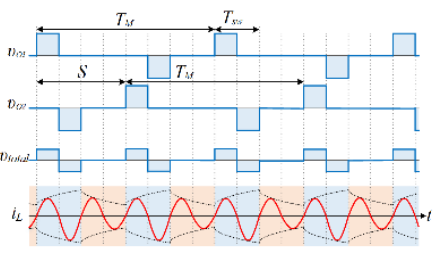

(f)

Figure 6. Voltage waveforms of $v_{O l}, v_{O_{2}}$, and $v_{\text {total }}$, and current waveforms of $i_{L}$ in case of: (a) $(k ; m ; n)=(5 ; 4 ; 1)$ and $S=0$; (b) $(k ; m ; n)=(5,4,1)$ and $S=1$; (c) $(k ; m ; n)=(5 ; 4 ; 1)$ and $S=2 ;(\mathrm{d})$ combained $(k ; m ; n)=(2.5 ; 0.5 ; 2)$ with

$(k ; m ; n)=(1.5 ; 0.5 ; 1)$ and $S=0 ;(\mathrm{e})$ combained $(k ; m ; n)=(2.5 ; 0.5 ; 2)$ with $(k ; m ; n)=(1.5 ; 0.5 ; 1)$ and $S=1 ;$ (f) combained $(k ; m ; n)=(2.5 ; 0.5 ; 2)$ with $(k ; m ; n)=(1.5 ; 0.5 ; 1)$ and $S=2$.

The similar pattern of $v_{\text {total }}$ can be obtained without interleaving of patterns of the PDM signals, but with the different patterns of PDM signals of each channel. In this case, to reduce the current amplitude fluctuation, it is advisable that the modulation is only in one of the $N$ channels and the modulation signals in

Soft start-up strategy of pulse-density-modulated series-resonant converter for ... (Pavlo Herasymenko) 
the other ones are 0 and/or 1 . This kind of modulation can be named as "stepped PDM" since modulation begins to act only in one channel, and when the modulation signal in this channel becomes steady-state 0 , the modulation starts to act in other channel, and so on to the last of the $N$ channels. In Figure 7 it is shown how to obtain the same pattern of vtotal when the interleaved or stepped PDM controls is being used. Anyway, using these kinds PDM allows to reduce the free-wheeling interval of $i_{L}$ or avoid it at all.

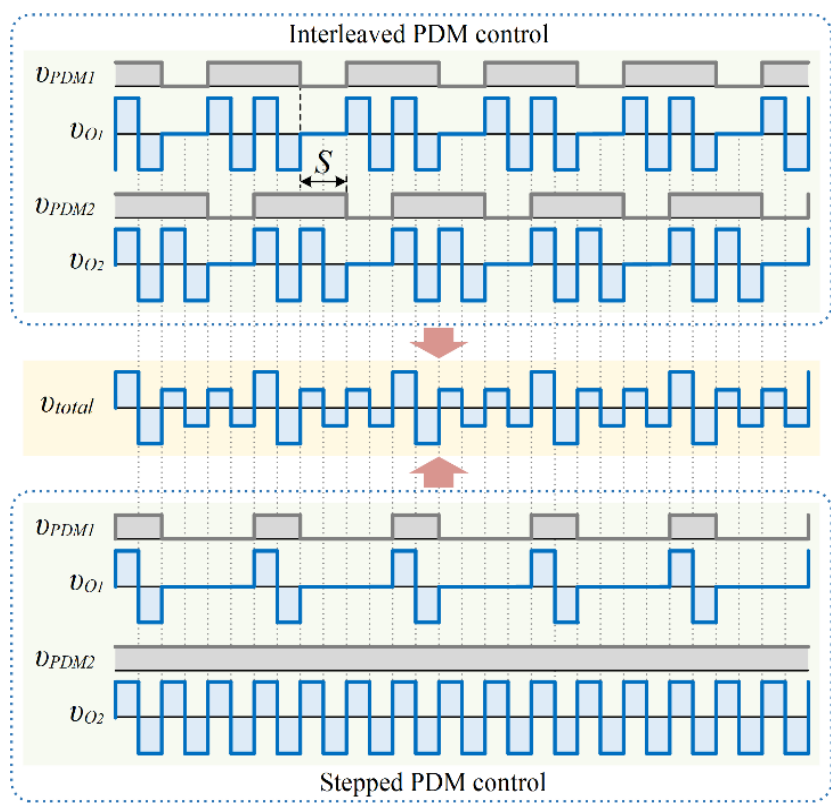

Figure 7. Interleaved PDM control vs. stepped PDM control

\section{THE PROPOSED START-UP STRATEGY OF PDM CONVERTER}

As stated in Section 2.2, the inverter output current can be controlled by different PDM techniques. For these techniques there can be selected combinations of $(k ; m ; n)$ which provide a fewer free-wheeling interval. The analysis conducted in Section 2.3 revealed that the use of PDM in the start-up process can lead to NON-ZVS commutation modes of the transistors, in particular - switching of the SRI transistors onto open anti-parallel diodes, due to the difference between the frequencies $\omega_{\text {pll }}$ and $\omega_{s w}$, and also the duration of the free-wheeling interval. In addition, it was shown that the use of the interleaved or stepped PDM control reduces the duration of the free-wheeling interval. In this section, on the basis of the analysis conducted above, the algorithm of the soft start-up strategy for PDM converter to provide ZVS of transistors and limiting the inrush current of the converter is proposed as shown in Figure 8. The strategy consists of the following steps:

1) Selecting the PDM technique to control $i_{L}$ :

- traditional PDM (Case I) - has high amplitude fluctuation of $i_{L}$, long duration of the free-wheeling interval, and is simple to implement;

- enhanced PDM (Case II) - has fewer amplitude fluctuation of $i_{L}$, and less duration of the free-wheeling interval comparting with traditional PDM, but is more complex to implement;

- enhanced PDM (Case III) - has the fewest amplitude fluctuation of $i_{L}$, and less duration of the freewheeling interval, but there is a DC component of $v_{O}$.

2) Selecting combinations $(k ; m ; n)$ (for the combinations with the same $D$ preference has to be given to the combination with the smaller value of $n$; some of the combinations $(k ; m ; n)$ can be combined to get additional points and some can be excluded).

3) Using an $N$-channel modular converter (based on the series connection of $N$ inverters) and using the interleaved or stepped PDM control for this converter. The more channels modular converter contains, the fewer are the fluctuation level of $i_{O}$ and the duration of the free-wheeling interval and the higher is the cost of the converter.

4) In the case of using the interleaved PDM control-for the selected combinations $(k ; m ; n)$ determining the shift $S$ which provides a fewer duration of the free-wheeling interval of $i_{L}$. 


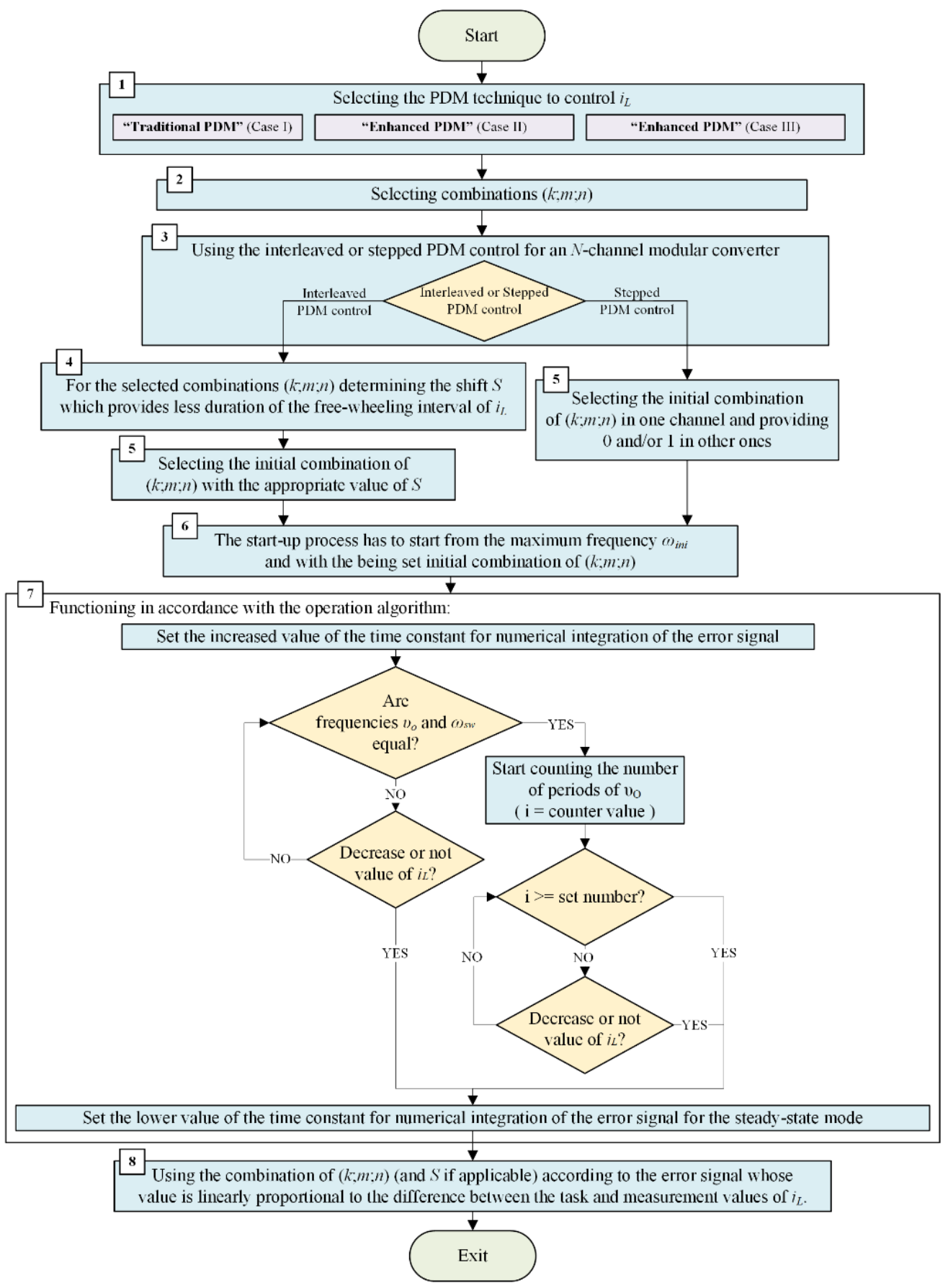

Figure 8. Algorithm of the proposed start-up strategy of PDM converter

5) In the case of using the interleaved PDM control - selecting the initial combination of $(k ; m ; n)$ with the appropriate value of $S$. In the case of using the stepped PDM control - selecting the initial combination of $(k ; m ; n)$ in one channel and providing 0 and/or 1 in other ones.

Initial combination of $(k ; m ; n)$ with the shift $S$, in the case of the interleaved PDM control, or initial combination of $(k ; m ; n)$ in one channel with 0 and/or 1 in other ones, in the case of using the stepped PDM control, must be selected so that in the case of starting on the workpiece-free induction coil, the inrush current would be limited at an acceptable level.

6) The start-up process has to start from the maximum frequency $\omega_{\text {ini }}$ and with the being set initial combination of $(k ; m ; n)$.

7) Functioning in accordance with the operation algorithm which is depicted in Figure 7. 
Step 7 of the proposed strategy is executed during the interval when the PLL system changes the frequency of its generator from $\omega_{i n i}$ to $\omega_{s w}$. In this step, the error signal value must be considered only if it matches the combination $(k ; m ; n)$ with the pulse density $D$ less than that of the initial combination. Also, during this step within a set number of periods of $v_{O}$ (when the frequency of $v_{O}$ reaches $\omega_{s w}$ ), the value of the time constant for numerical integration of the error signal has to be larger than its value during the steady-state mode. These two points are due to the fact that the initial combination can be replaced by a combination that will not be able to limit the inrush current to the desired level due to the inertia of measuring the value of $i_{L}$ by the control system.

8) Using the combination of $(k ; m ; n)$ and $S$ according to an error signal whose value is linearly proportional to the difference between the task and measurement values of $i_{L}$.

Step 8 is the last step of the proposed strategy; it corresponds to the beginning of the steady-state mode. In the steady-state mode the control system continues to operate in accordance with this step and the selected PDM technique, PDM parameters, and interleaved/stepped PDM control.

As the inverters are connected in series with matching transformers, the output currents of the inverters are equal $\left(i_{O I}=i_{O 2}=i_{O}\right)$ and $i_{O}$ is connected with $i_{L}$ trough the transformer turns ratio. To provide ZVS operating modes, it is important to control phase-shift between $v_{O}$ and $i_{O}$. Therefore, it is expedient to measure and regulate the value of $i_{O}$.

\section{IMPLEMENTATION AND EXPERIMENTAL RESULTS}

\subsection{Experimental Setup and its Specifications}

The experimental setup of the interleaved PDM converter was used to experimentally verify the effectiveness of the proposed start-up strategy [30]. The schematic depiction of the setup is illustrated in Figure 9. The setup works with an operating frequency from $50 \mathrm{kHz}$ up to $100 \mathrm{kHz}$, contains two channels of FB-SRIs $(N=2)$ and has total output power up to $2.5 \mathrm{~kW}$. The setup is powered by the $220 \mathrm{VAC} 50 \mathrm{~Hz}$ main. Each of the FB-SRIs uses four SiC MOSFETs (SCT3120ALGC11). The control system is based on the STM32H743ZIT6 microcontroller (MC). The transformation ratio of each matching transformer is 64:1. Main specifications of the experimental setup are summarized in Table 1.

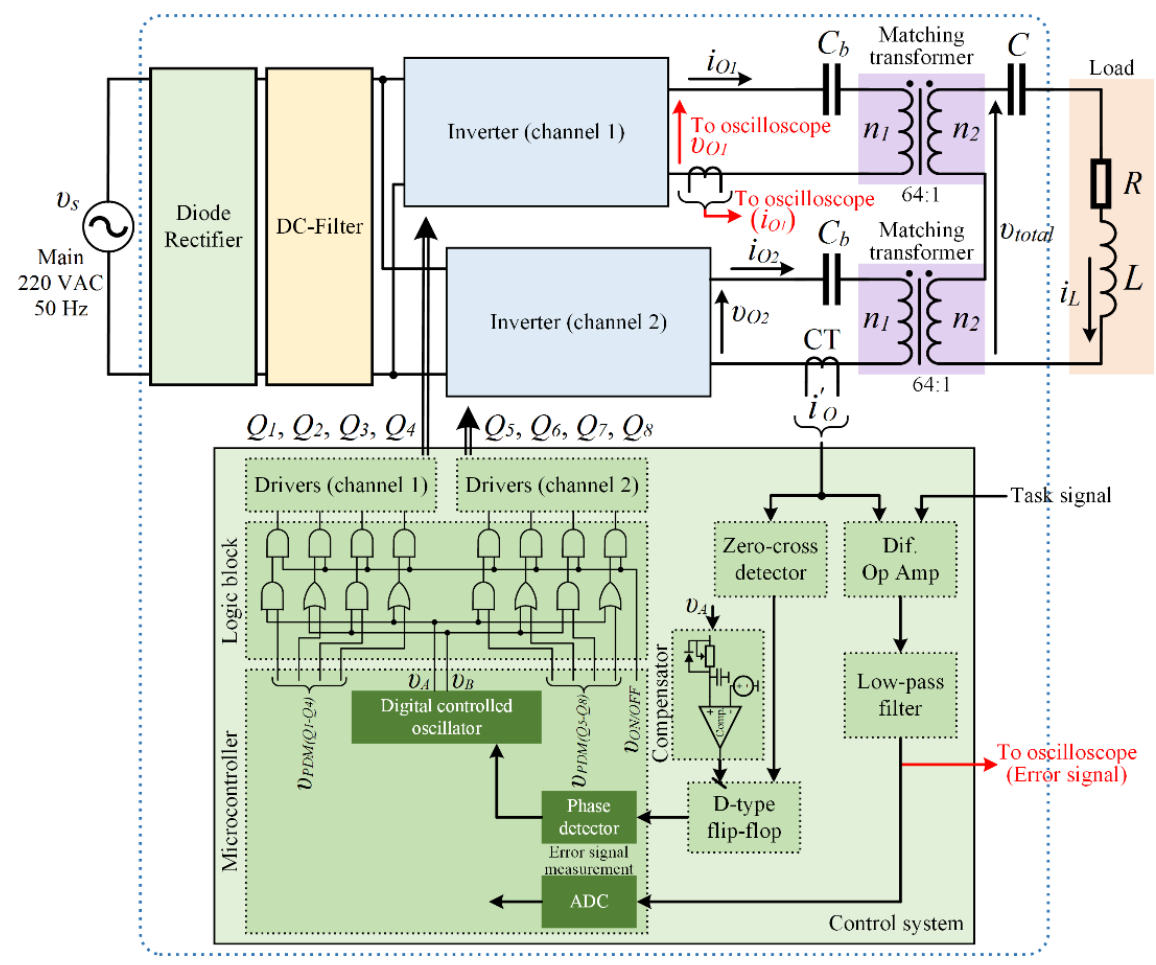

Figure 9. Schematic depiction of the experimental setup 
Digital controlled oscillator (DCO) of MC forms two complimentary signals $v_{A}$ and $v_{B}$ with the constant value of the dead-time $T_{D T}=500 \mathrm{~ns}$. MC forms four PDM signals $v_{P D M(Q 1-Q 4)}$ for the first channel and four PDM signals $v_{P D M}(Q 5-Q 8)$ for the second channel of the converter. The PDM signals $v_{P D M}(Q 5-Q 8)$ repeat $v_{P D M}(Q 1-Q 4)$ with the shift $S$ in accordance with PDM combination given in Table 2. Signals $v_{A}, v_{B}, v_{P D M(Q 1-Q 4)}$, and $V_{P D M}(Q 5-Q 8)$ are coming to the logic block where transistor signals are formed. The drivers are used for current amplifying of output signal of the logic block as well as for its galvanically isolation. The signal $v_{\text {ON/OFF }}$ is used to completely turn off, if necessary, all transistors of the converter (for inactive or emergency state). The load current $i_{L}$ is connected with the output currents $\left(i_{O 1}, i_{O 2}\right)$ of the converter's channels by the matching transformers. These currents are monitored by measuring the current of one channel $\left(i_{O}^{\prime}\right)$ with the current transformer. Load current regulation is carried out in accordance with the error signal value by PI control. The average value of the error signal is linearly proportional to the difference between the set value of the task signal and measured value of the output current. The error signal is then being passed through a low-pass filter as shown in Figure 8. A phase-locked loop (PLL) system is implemented with the aid of the MC as shown in Figure 10. This system uses a D-type flip-flop and a compensator, the latter is used to compensate the propagation delay between $v_{A}$ and $v_{O 1}$ signals, as well as to provide the desired time shift between $i_{O 1}$ and $v_{O I}$. The D-type flip-flop clamps the logic signal of the zero-current detector by the rise edge of the output signal of the compensator. Based on the signal from the D-type flip-flop, the MC changes the operating frequency by increasing/decreasing the counter value of DCO [19].

Table 1. Parameters of the Experimental Setup

\begin{tabular}{ccc}
\hline Item & Symbol & Value \\
\hline AC main & $v_{s}$ & $220 \mathrm{VAC} 50 \mathrm{~Hz}$ \\
Number of inverter channels & $N$ & 2 \\
Rated output power & $P$ & $2.5 \mathrm{~kW}$ \\
(each channel) & & $(1.25 \mathrm{~kW})$ \\
Operating frequency & $f_{s w}$ & $50-100 \mathrm{kHz}$ \\
Transformer turns ratio of each channel & $n_{l}: n_{2}$ & $64: 1$ \\
Capacitor & $C$ & $0.033 \mu \mathrm{F} \times 370=12.21 \mu \mathrm{F}$ \\
\hline
\end{tabular}

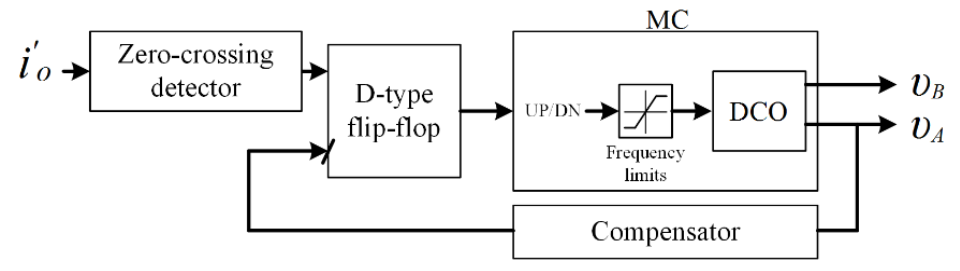

Figure 10. Block diagram of the PLL system.

Figure 11 presents two photographs of the experimental setup used in the described below experiments.
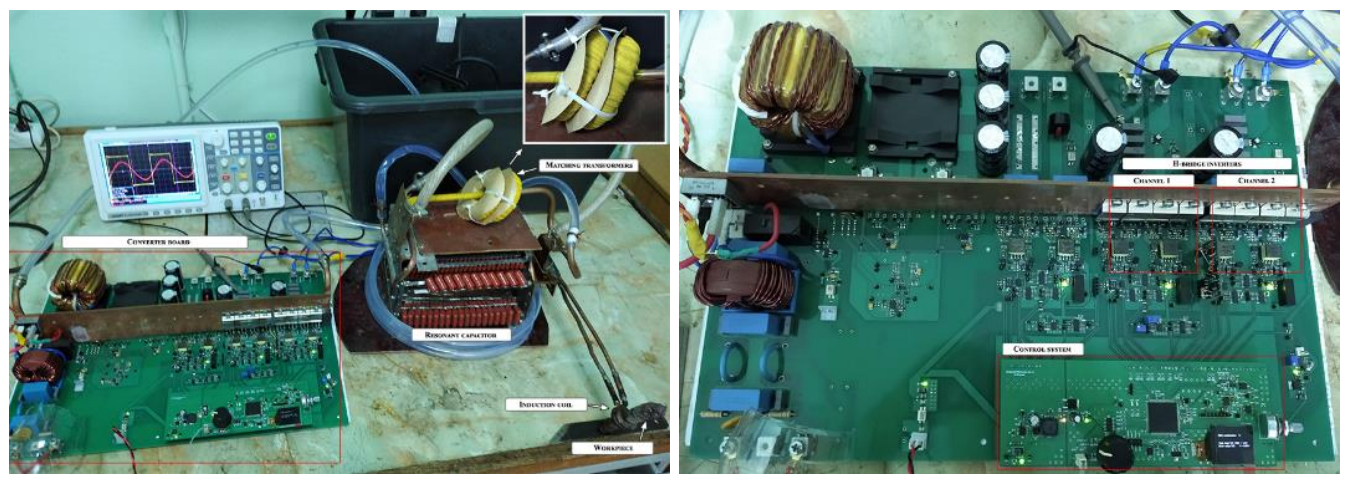

Figure 11. The experimental setup of the interleaved PDM series-resonant converter 
The selected and stored in MC memory combinations of $(k ; m ; n)$ and their shifts $S$ are shown in Table 2. Some of the combinations have been obtained by combining two nearby combinations. The combination of $(k ; m ; n)=(1.5 ; 0.5 ; 1)$ has been used by the control system as the initial one.

Table 2. PDM combinations $(k ; m ; n)$ and shifts $S$ stored in the MC

\begin{tabular}{ccc}
\hline$D$ & $(k ; m ; n)$ & $S$ \\
\hline 1 & $(10 ; 10 ; 0)$ & 0 \\
0.94 & $(16 ; 15 ; 1)$ & 8 \\
0.9 & $(10 ; 9 ; 1)$ & 5 \\
0.86 & $(7 ; 6 ; 1)$ & 4 \\
0.83 & $(6 ; 5 ; 1)$ & 3 \\
0.8 & $(5 ; 4 ; 1)$ & 2 \\
0.75 & $(4 ; 3 ; 1)$ & 2 \\
0.67 & $(3 ; 2 ; 1)$ & 1 \\
0.6 & $(2 ; 1 ; 1)$ & 1 \\
0.5 & $(1.5 ; 0.5 ; 1)$ & 1 \\
0.4 & combining $(3 ; 2 ; 1)$ and $(2 ; 1 ; 1)$ & 1 \\
0.33 & $(2.5 ; 0.5 ; 2)$ & 1 \\
0.25 & $(3.5 ; 0.5 ; 3)$ & 1 \\
0.2 & combining $(2.5 ; 0.5 ; 2)$ and $(1.5 ; 0.5 ; 1)$ & 1 \\
0.17 & combining $(3.5 ; 0.5 ; 3)$ and $(2.5 ; 0.5 ; 2)$ & 1 \\
0.14 & combining $(4.5 ; 0.5 ; 4)$ and $(3.5 ; 0.5 ; 3)$ & 1 \\
0.13 & $(4.5 ; 0.5 ; 4)$ & 2 \\
0.11 & $(5.5 ; 0.5 ; 5)$ & 2 \\
0.09 & $(10 ; 0 ; 10)$ & 3 \\
0 & & 0 \\
\hline
\end{tabular}

\subsection{Experimental Waveforms and Results}

Figure 12 shows the experimental waveforms of the error signal and output current in one of two setup's channels. The waveforms have been obtained under three different load conditions: Condition I - a workpiece is placed in an induction coil and the setup works almost with the full rated output power, $Q \approx 6.5$ as shown in Figure 12(a); Condition II - the workpiece is placed in the induction coil, but its equivalent resistance is less than that in the first case, $Q \approx 8$ as shown in Figure 12(b); Condition III - the setup works on the workpiece-free induction coil, $Q \approx 19.5$ as shown in Figure $12(\mathrm{c})$.

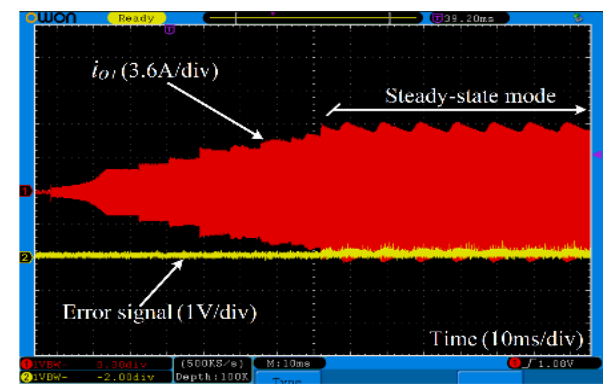

(a)

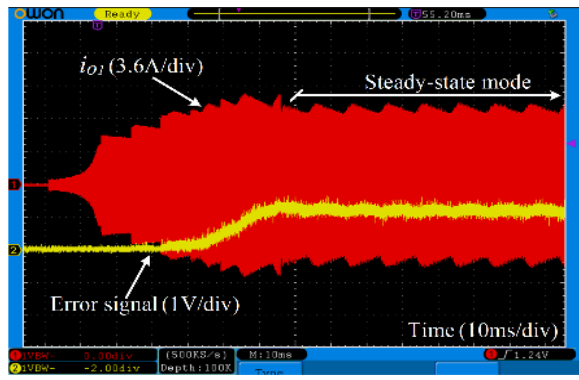

(b)

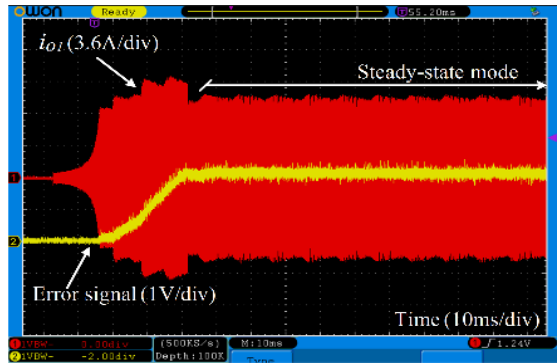

(c)

Figure 12. Experimental waveforms of $i_{O 1}$ and error signal in case of different load conditions,

(a) Condition I, (b) Condition II, (c) Condition III 
As it can be seen from these waveforms, the current amplitudes within the start processes are not much higher than they are within the steady-state mode. There is no an excessive inrush current in the case of Condition I, as shown in Figure 12(a) and the current rise is gradual. In the case of Condition II as shown in Figure 12(b) the maximal value of the inrush current does not greatly exceed the maximal amplitude of the current under the steady-state mode. The case of Condition III as shown in Figure 12(c) is the worst because the value of the inrush current is the maximal. But even in this case its value is not much higher than the maximal steady-state current amplitude, and the maximum current amplitude within start-up processes exceeds the maximum steady-state current amplitude by no more than $30 \%$. It can be asserted that such limitation of the inrush current is enough to limit the maximum amplitude of the current through the converter transistors and the maximum voltage across the capacitor $C$. It is possible to add more channels to the converter to further reduce the inrush current. So, it can be argued that the proposed start-up strategy of the PDM converter is very useful, as it is evidenced by the obtained experimental waveforms of the inverter output current.

Figure 13 shows the waveforms of switch $i_{O I}$ and $v_{O I}$ under the steady-state mode for the mentioned above load conditions. There are no problems with commutation of SRI transistors, because it occurs in ZVS and quasi-ZCS commutation modes. The set value of $T_{D T}$ is enough to ensure that there are ZVS/quasi-ZCS commutation modes under deep current regulation within the operating frequency range as shown in Figure 14.

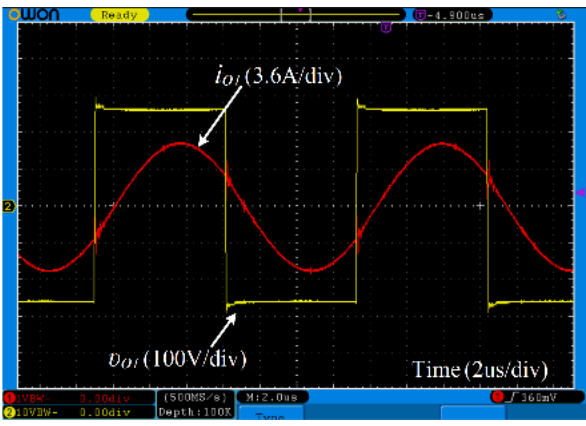

(a)

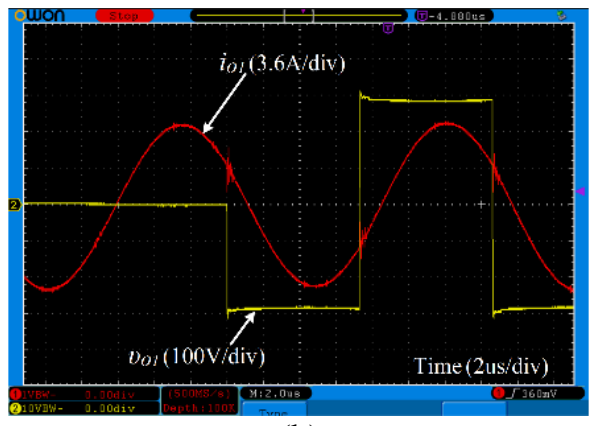

(b)

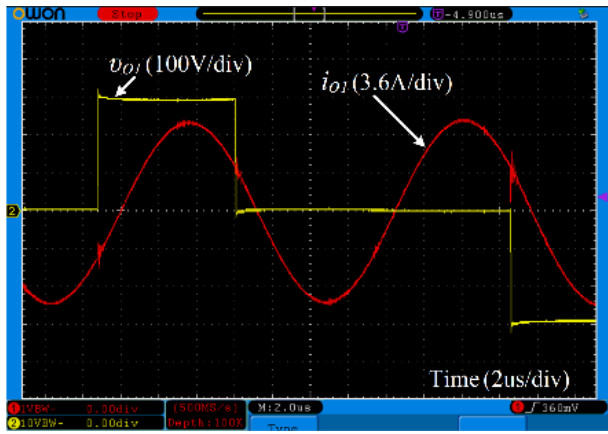

(c)

Figure 13. Experimental waveforms of $i_{O I}$ and $v_{O I}$ in steady-state mode,

(a) Condition I $(D=1)$. (b) Condition II $(D=0.8)$. (c) Condition III $(D=0.33)$

Figure 15 shows experimental waveforms of switch $i_{O I}$ and $v_{O I}$ within start-up processes for the mentioned above load conditions. There are also no problems with commutation modes of the transistors. Therefore, the start-up process may be considered as "soft". In the experiments described above the operation frequency under the steady-state mode was in the frequency range of $68 \mathrm{kHz}$ to $71 \mathrm{kHz}$, depending on the workpiece of the induction coil. The initial frequency of the control system was equal to the maximum frequency of the operating range. 


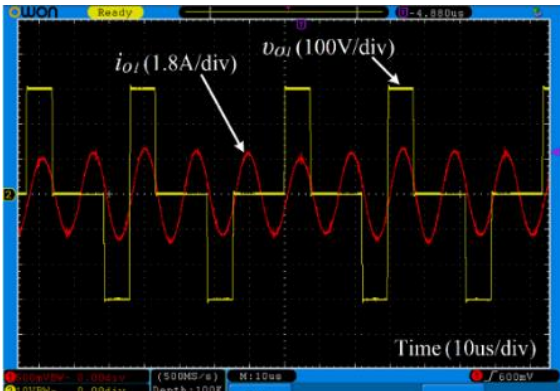

(a)

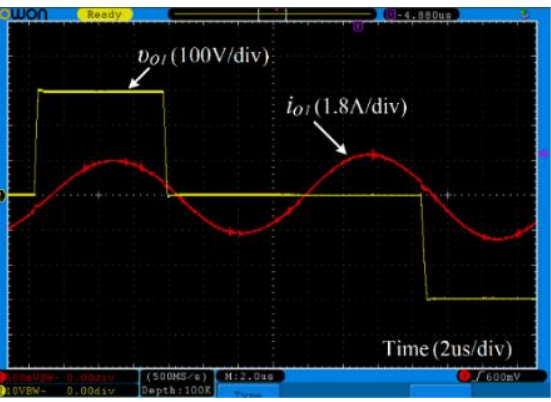

(b)

Figure 14. Experimental waveforms of $i_{O I}$ and $v_{O I}$ in steady-state mode for Condition I under deep current regulation, (a) time 10us/div, (b) time 2us/div

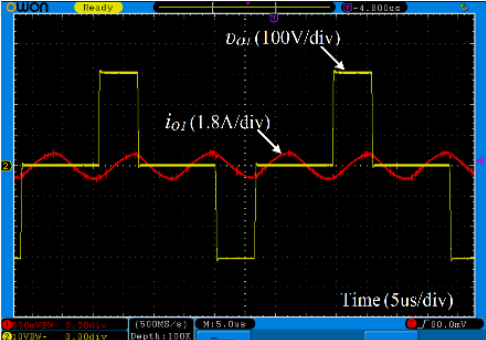

(a)

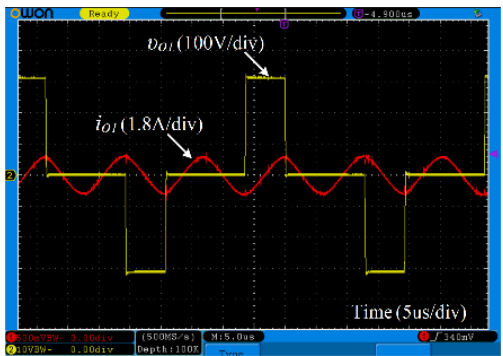

(d)

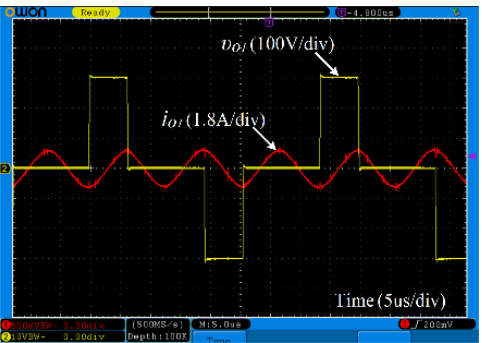

$(\mathrm{g})$

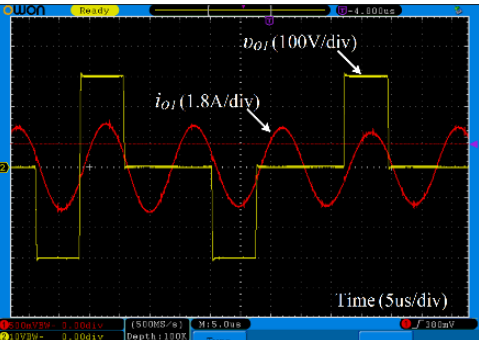

(b)

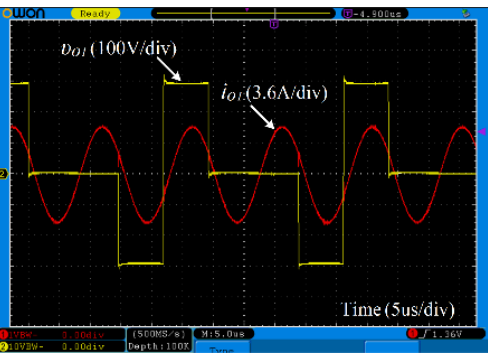

(e)

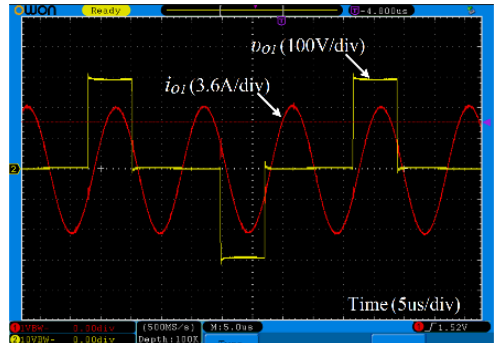

(h)

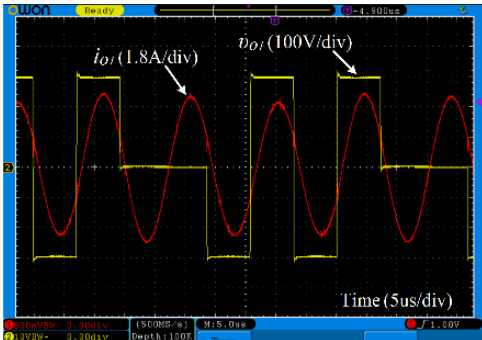

(c)

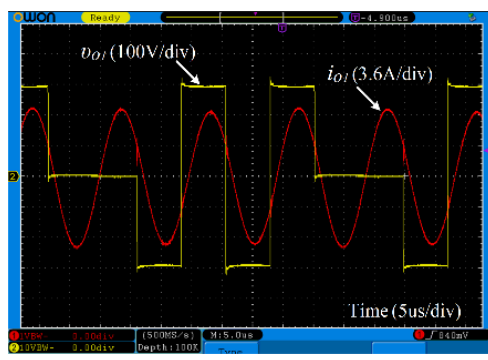

(f)

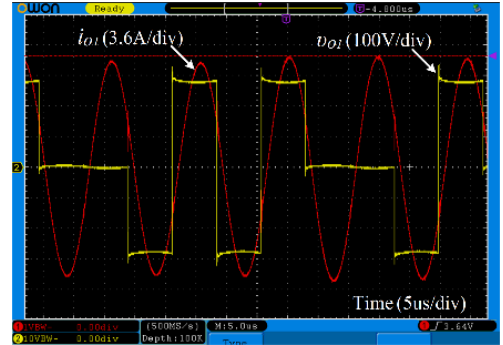

(j)

Figure 15. Experimental waveforms of $i_{O I}$ and $v_{O I}$ within start-up process, (a)-(c) Condition I, (d)-(f) Condition II, (g)-(h) Condition III

\section{CONCLUSION}

This paper has proposed the soft start-up strategy of the PDM series-resonant converter for induction heating application. The main features of the proposed strategy include using the interleaved or stepped PDM control, the initial combination of PDM at the beginning of the start-up process, and the described above operating algorithm during the start-up process. The proposed algorithm of the start-up strategy allows to obtain limiting of the inrush current during the start-up process with zero-voltage switching commutation modes of the converter transistors. As a result, the output current of series-resonant converter and voltage across the 
capacitor of the resonant circuit during the start-up process are limited, and the maximum current amplitude within start-up processes exceeds the maximum steady-state current amplitude by no more than $30 \%$. It is possible to add more channels to the converter to further reduce the inrush current. It has been verified with the aid of the $2.5 \mathrm{~kW}$ experimental setup of the interleaved PDM converter that the proposed soft start-up strategy makes it possible to limit the maximal value of the inrush current and ensure zero-voltage switching operating under the start-up process.

\section{REFERENCES}

[1] Young-Sup Kwon, Sang-Bong Yoo and Dong-Seok Hyun, "Half-bridge series resonant inverter for induction heating applications with load-adaptive PFM control strategy," in Proc. IEEE APEC'99, Dallas, 1999, pp. 575-581.

[2] M. Antchev and H. Antchev, "Dead time influence on operating modes of transistor resonant inverter with pulse frequency modulation (PFM)," International Journal of Power Electronics and Drive System, vol. 10, no. 4, pp. 1815-1822, Dec. 2019.

[3] S. Nagai, H. Nagura, M. Nakaoka and A. Okuno, "High-frequency inverter with phase-shifted PWM and loadadaptive PFM control strategy for industrial induction-heating," in Proc. IEEE Ind. Appl. Conf. Twenty-Eighth IAS Annu. Meeting, Toronto, Ontario, Canada, 1993, pp. 2165-2172.

[4] Yue lu Feng, H. Shirai, K. Oleg, A. Okuno and M. Nakaoka, "Pulse density modulated zero current soft-switching series resonant high frequency inverter for consumer induction-heated roller," in Proc. IEEE PESC2002, Cairns, Qld., Australia, vol.4, pp. 1884-1891, 2002.

[5] L. Grajales, J.A. Sabate, K.R. Wang, W.A. Tabisz and F.C. Lee, "Design of a 10 kW, 500 kHz phase-shift controlled series-resonant inverter for induction heating," in Conf. Record of the 1993 IEEE Ind. Appl. Conf. Twenty-Eighth IAS Annu. Meeting, Toronto, Ontario, Canada, 1993, pp. 843-849.

[6] N. Parida, V. Kumari, D. V. Bhaskar and T. Maity, "Power control techniques used in high frequency induction heating applications," in Proc. ICCPCT-2015, Nagercoil, pp. 1-6, 2015.

[7] L. Grajales and F.C. Lee, "Control system design and small-signal analysis of a phase-shift-controlled series-resonant inverter for induction heating," in Proc. PESC '95, Atlanta, GA, USA, pp. 450-456, 1995.

[8] H. Fujita and H. Akagi, "Pulse-density-modulated power control of a $4 \mathrm{~kW}, 450 \mathrm{kHz}$ voltage-source inverter for induction melting applications," IEEE Trans. Ind. Appl., vol. 32, no. 2, pp. 279-286, 1996.

[9] H. Sugimura, H. Omori, H. W. Lee and M. Nakaoka, "PDM controlled series load resonant soft switching high frequency inverter for induction heated toner fixing outer roller with inner cylindrical working coil stator," in Proc. IEEE IPEMC2006, Shanghai, China, pp. 1-5, 2006.

[10] V. Esteve et al., "Using pulse density modulation to improve the efficiency of IGBT inverters in induction heating applications," in Proc. IEEE PESC2007, Orlando, FL, USA, pp. 1370-1373, 2007.

[11] J. Shen, H. Ma, W. Yan, J. Hui and L. Wu, "PDM and PSM hybrid power control of a series-resonant inverter for induction heating applications," in Proc. IEEE ICIEA2006, Singapore, 2006, pp. 1-6.

[12] H. Kifune and Y. Hatanaka, "Resonant frequency tracking control by using one CT for high frequency inverter," in Proc. 13th European Conf. on Power Electron. and Appl., Barcelona, Spain, pp. 1-7, 2009.

[13] Z. Waradzyn, A. Skala and R. Kieronski, "Fixed-frequency control strategies for a series-resonant inverter for induction heating - comparison of properties," Przeglad Elektrotechniczny, vol. 92, no. 3, pp. 114-117, 2016.

[14] A. Pholsriphim, S. Nurach and W. Lenwari, "Half-bridge resonance inverter for induction heating using digitalcontrolled pulse density modulation technique," in Proc. IEEE ICIEA2017, Siem Reap, pp. 1084-1086, 2017.

[15] G. M. Segura, "Induction heating converter's design, control and modelingapplied to continuous wire" PhD dissertation, Dept. d'Enginyeria Electrica, Univ. Politecnica de Catalunya, Barcelona, Spaine, 2012.

[16] Jingang Hu, Chuang Bi, Kelin Jia and Yong Xiang, "Power control of asymmetrical frequency modulation in a fullbridge series-resonant inverter," IEEE Trans. Power Electron., vol. 30, no. 12, pp. 7051-7059, 2015.

[17] P. Y. Herasymenko, "A transistor resonant voltage inverter with pulse density modulation for induction heating equipment," Technical Electrodynamics, no. 6, pp. 24-28, 2015.

[18] V. Esteve et al., "Enhanced pulse-density-modulated power control for high frequency induction heating inverters," IEEE Trans. Ind. Electron., vol. 66, no. 11, pp. 6905-6914, 2015.

[19] P. Herasymenko, V. Hutsaliuk, V. Pavlovskyi and O. Yurchenko, "A software phase-locked loop of control system of a series-resonant voltage-source inverter for induction heating equipment," in Proc. IEEE UKRCON2017, Kyiv, Ukraine, pp. 384-389, 2017.

[20] M. Fan, L. Shi, Z. Yin, L. Jiang and F. Zhang, "Improved pulse density modulation for semi-bridgeless active rectifier in inductive power transfer system," IEEE Trans. Power Electron., vol. 34, no. 6, pp. 5893-5902, 2019.

[21] V. Geetha and V. Sivachidambaranathan, "An AC-AC high frequency pulse density modulated full bridge series resonant converter for induction heating application," International Journal of Electrical and Computer Engineering, vol. 9 , no. 4, pp. 2238-2246, 2019

[22] H. Fujita and H. Akagi, "Control and performance of a pulse-density-modulated series-resonant inverter for corona discharge processes," IEEE Trans. Ind. Appl., vol. 35, no. 3, pp. 1320-1325, 1999.

[23] E. J. Dede et al., "Soft switching series-resonant converter for induction heating applications," in Proc. IEEE PEDS1995, Singapore, Singapore, pp. 689-693, 1995.

[24] M. R. Ahmed, R. Todd and A. J. Forsyth, "Predicting SiC MOSFET behaviour under hard-switching, soft-switching, and false turn-on conditions," IEEE Trans. Ind. Electron., vol. 64, no. 11, pp. 9001-9011, Nov. 2017. 
[25] T. -. Wu and J. -. Hung," A PDM controlled series-resonant multi-level converter applied for X-ray generators," in PESC1999, Charleston, SC, USA, pp. 1177-1182, 1999.

[26] Hui Zhu, Chengyong Wang, Yonglong Peng, and Yabin Li, "The study of novel PDM-based induction heating frequency tracking control," in Proc. IEEE IPEMC2012, Harbin, China, pp. 2893-2897, 2012.

[27] H. Calleja and J. Pacheco, "Power distribution in pulse-density modulated waveforms," in Proc. IEEE PESC2000, Galway, Ireland, pp. 1457-1462, 2000.

[28] A.P. Hu, G.A. Covic and J.T. Boys, "Direct ZVS start-up of a current-fed resonant inverter," IEEE Trans. Power Electron., vol. 21, no. 3, pp. 809-812, 2006.

[29] D. Yang, C. Chen, S. Duan, J. Cai and L. Xiao, "A variable duty cycle soft startup strategy for LLC series resonant converter based on optimal current-limiting curve," IEEE Trans. Power Electron., vol. 31, no. 11, pp. 7996-8006, 2016.

[30] P. Herasymenko, "Soft Start-up Output Current of PDM-based Series-Resonant Converter for Induction Heating Application," in Proc. IEEE UKRCON2019, Lviv, Ukraine, pp. 570-575, 2019.

[31] H. Sarnago, Ó. Lucía, A. Mediano and J. M. Burdío, "Analytical model of the half-bridge series-resonant inverter for improved power conversion efficiency and performance," IEEE Trans. Power Electron., vol. 30, no. 8, pp. 41284143, 2015.

[32] A. Okuno, H. Kawano, J. Sun, M. Kurokawa, A. Kojina and M. Nakaoka, "Feasible development of soft-switched SIT inverter with load-adaptive frequency-tracking control scheme for induction heating," IEEE Trans. Ind. Appl., vol. 34, no. 4, pp. 713-718, 1998.

[33] N.S. Bayindir, O. Kukrer and M. Yakup, "DSP-based PLL-controlled 50-100 kHz 20 kW high-frequency induction heating system for surface hardening and welding applications," IEE Proc. - Electric Power Appl., vol. 150, no. 3, pp. 365-371, 2003.

[34] H. A. Zied, P. Mutschler and G. Bachmann, "A modular IGBT converter system for high frequency induction heating applications," in Proc. PCIM Conf., 2002.

[35] E. J. Dede, J. Jordán and V. Esteve, "The practical use of SiC devices in high power, high frequency inverters for industrial induction heating applications," in Proc. IEEE SPEC2016, Auckland, New Zealand, pp. 1-5, 2016. 